\title{
Setons in the Treatment of Anal Fistula: Review of Variations in Materials and Techniques
}

\author{
Gokulakkrishna Subhas Jasneet Singh Bhullar Ahmed Al-Omari \\ Amruta Unawane Vijay K. Mittal Ralph Pearlman \\ Department of Surgery, Providence Hospital and Medical Centers, Southfield, Mich., USA
}

\section{Key Words}

Seton - Anal fistula · Crohns disease - Loose seton •

High fistula

\begin{abstract}
Aim: Anorectal fistulas have been a common surgical problem since ancient times. Age-old seton techniques are still practiced successfully in the treatment of complex anal fistulas. Many variations in materials and techniques are described in the literature. The selection of a seton type and technique depends on personal preferences. Our aim was to put together all the available variations in materials and techniques for seton treatment. This comprehensive review will help the surgeon to become more familiar with the various options available with regard to materials and techniques. Methods: A review of the literature using Medline was done using the keywords 'anal fistula' and 'seton'. All articles published in English were reviewed. The articles which had variations in materials and techniques for seton treatment were studied. Results: Various aspects of variations in materials, insertion techniques, maintenance of tension, mechanisms of action, drainage techniques and changing the seton have been elaborated in detail. Conclusions: Throughout this paper we present the various available variations in setons with regard to materials, placement and maintenance techniques. This study will help clinicians in
\end{abstract}

\section{KARGER \\ Fax +41613061234 \\ E-Mail karger@karger.ch}

www.karger.com
(C) 2012 S. Karger AG, Basel

0253-4886/12/0294-0292\$38.00/0

Accessible online at: www.karger.com/dsu choosing a new seton variation or modifying their current method of treatment with setons.

Copyright $\odot 2012$ S. Karger AG, Basel

\section{Introduction}

High transsphincteric fistulas involving the upper two-thirds of the external sphincter remain a surgical challenge because incontinence may result from the division of muscle involving more than one-third of the sphincter [1]. The principles of anal fistula surgery are to eliminate the fistula, prevent recurrence and preserve sphincter function [2]. In contrast to fistulotomy for low anal fistulas, a well-accepted, simple, safe, and efficient method is still lacking for high anal fistulas. Seton techniques still occupy an important position in the treatment of high anal fistulas. A seton can be any type of foreign material inserted through a fistulous track. Although setons have been used since Egyptian times, Hippocrates first detailed a method of application in the anal fistula. He suggested the use of 'horsehair wrapped about a lint thread' and advanced through the fistula by means of a director made of tin. The ends of the horsehair thread were intermittently tied about the enclosed muscle until the flesh was eaten through [3]. The word seton is derived from the Latin 'seta', meaning a bristle. Currently, many different materials have been used as setons, in- 
cluding silk, wire, elastic bands, Penrose drain, and nylon and plastic tubing [4].

The seton works by several mechanisms: (1) it helps in draining pus and controlling sepsis prior to definitive treatment; (2) it stimulates fibrosis and acts as a marker of the fistula tract for sphincter-sparing procedures such as fistula plug, fibrin glue and ligation of the intersphincteric fistula tract, and (3) the tight (cutting) seton promotes slow transection of the external sphincter muscle as a result of pressure necrosis with minimal separation of the cut ends $[5,6]$. Long-term seton drainage is a simple and efficient procedure in treating high anal fistulas in Crohn's disease [7].

Anorectal fistulas have been a common surgical problem since ancient times. Age-old seton techniques are still practiced successfully in the treatment of complex fistulas in ano. However, selection of a seton type and technique depends on personal preferences. We undertook a review of the literature to find out the different materials and variations in techniques used with setons. This comprehensive review will help the surgeon to become more familiar with the various options available with regard to the materials and techniques.

\section{Methods}

A Medline search was done using the keywords 'anal fistula' and 'seton'. All articles published in English were reviewed. Articles which had a variation in materials and techniques for seton use were selected for this review. The various aspects of variations in materials, insertion techniques, maintenance of tension, mechanisms of action, drainage tube mechanisms and changing the seton have been elaborated in detail below. The data from the case series published in 19 articles are outlined in table 1 .

\section{Variation in Seton Materials}

A variety of materials have been used - sutures, stainless steel wires, depezzar catheters, medicated ksharsootra, self-locking cables, silicone, thread, and rubber bands $[8,9]$. The ancient technique of treating all anal fistulas with a caustic chemical seton made from plant extract is known as kshara-sutra. A prospective randomized trial by Ho et al. [10], comparing ayurvedic cutting seton and fistulotomy for low fistula in ano, concluded that the chemical seton was more painful than conventional fistulotomy and there was no difference in time to wound healing, complications or functional outcome. Hanley [11] reported the use of a rubber-band seton in the surgical management of anterior abscess-anal fistulas and anterolateral fistulas in women with good functional results. Mentes et al. [5] and Chuang-Wei et al. [12] described the use of an elastic seton which was created by cutting a thin $(2-3 \mathrm{~mm})$ circular strip from a surgical glove, including its thicker sleeve.

Culp [3] described the use of a thin Penrose drain $\left(1 / 4^{-5 / 8}\right.$ in) as a primary operative seton in order to utilize its elastic properties. Traction was applied by a tie of heavy silk suture passed with a small non-cutting needle through the elastic drain to prevent slippage. Parks and Stitz [13] described the use of a braided nylon suture as a seton for complex fistulas. Armstrong et al. [14] described the use of a hollow 3-mm diameter silastic tube seton which allowed clear visualization of drained fistula tracks with MRI in the setting of ongoing perianal sepsis.

\section{Variation in Seton Insertion Technique}

Insertion of a seton is not always easy. This insertion is especially difficult in a high complex track. Grooved Lockhart-Mummery probes have been used to probe fistula tracks and help seton insertion. The groove is helpful in low simple tracks, but usually fails for high tracks as the seton tends to curl up within the abscess or fistula cavity. Other modifications of the probe to assist seton insertion include the inclusion of an eye near the tip of the probe through which the seton may be passed for withdrawal through the fistula. Seow-Choen [15] described the use of a railroad technique for seton insertion (fig. 1a). After successful probing of the fistula with a Lockhart-Mummery probe, an 8 -Fr feeding tube is used to cap the top of the probe. This fits snuggly and allows the probe to be withdrawn, drawing the feeding tube through the fistula. The seton material can then be passed easily through the lumen of the feeding tube, and the feeding tube removed thereafter. Gurer et al. [16] made use of plastic infusion line and olive-tip malleable metal guide for seton placement in the above technique (fig. 1b).

\section{Maintenance of Tension}

To ensure that the seton adequately cuts the tissue it is encircling, there should be a constant tension. Thompson et al. [17] described the use of leg strap and tourniquet (fig. 2a) to achieve constant tension in the seton. In the legstrap technique, a stout rubber band that has been previously attached to a safety pin is incorporated into the tied suture and is taped to the thigh. In the tourniquet method, the ends of the suture are threaded into a 12-Fr red rubber catheter after a series of knots have been placed at 


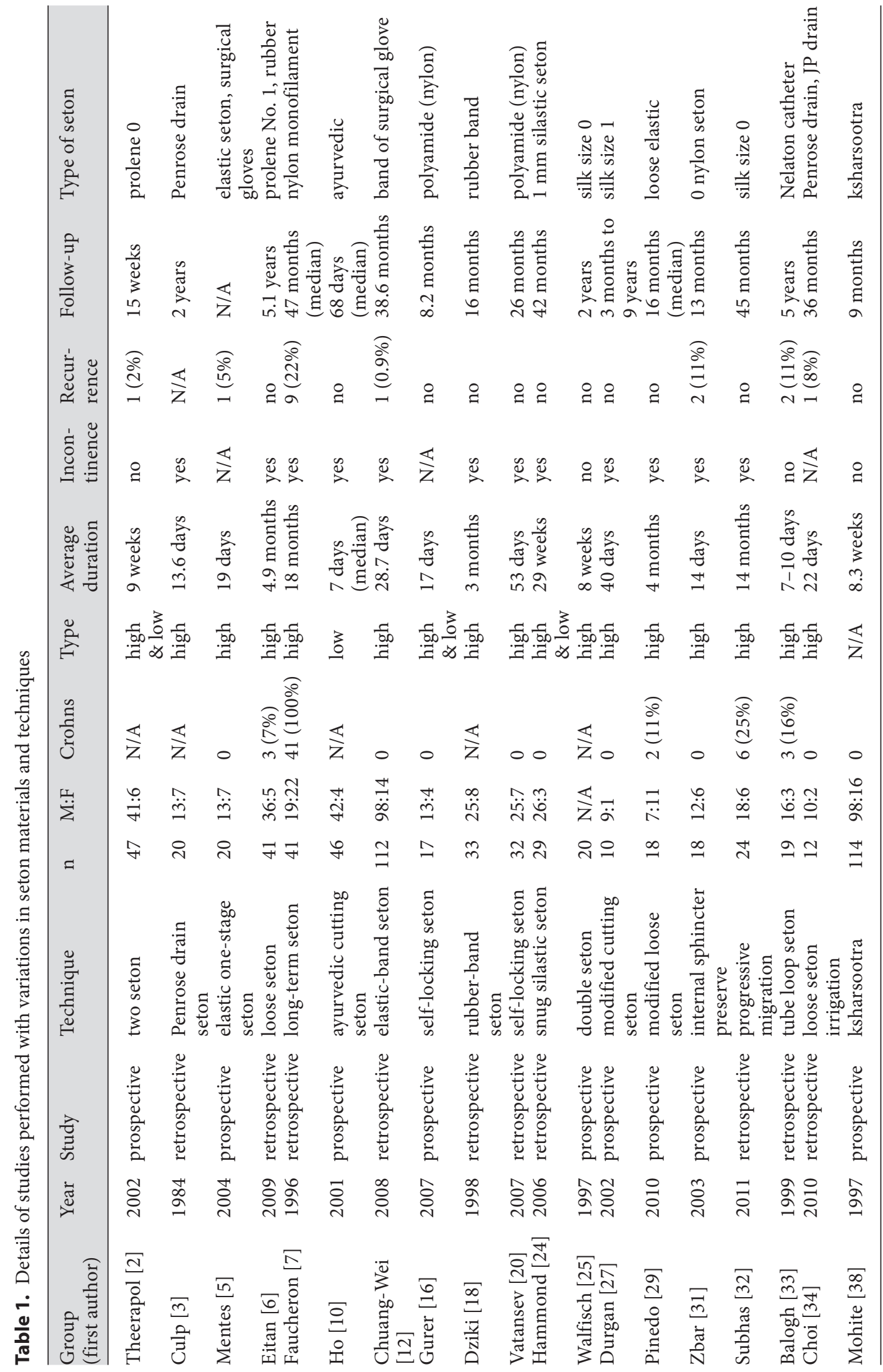



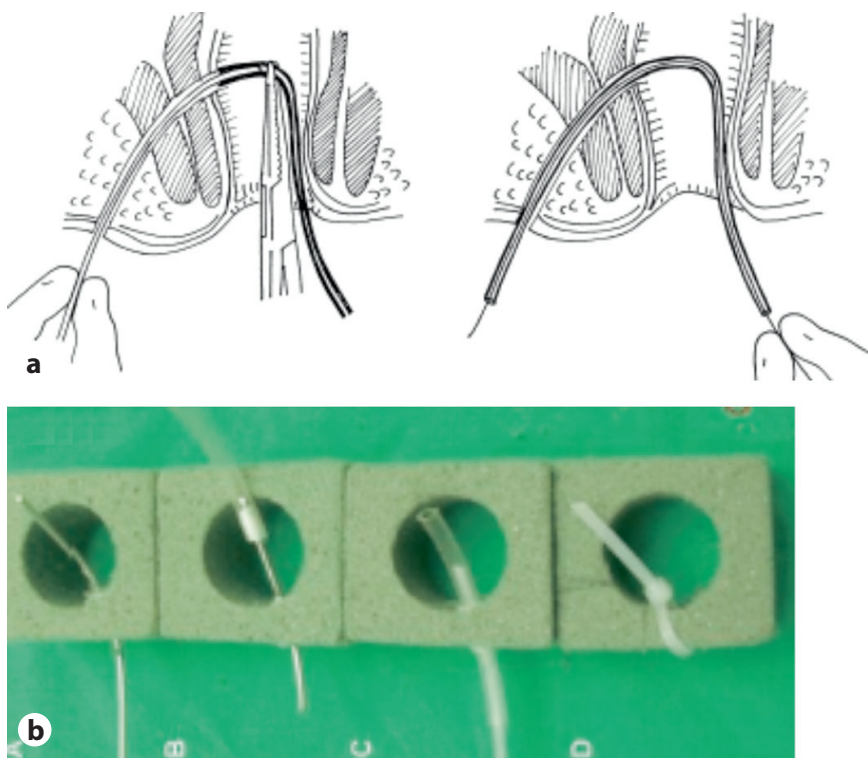

Fig. 1. Seton insertion. a Railroad technique using a 8-Fr feeding tube. b Placement of polyamide self-locking cable tie using a plastic infusion line.

$1-\mathrm{cm}$ intervals. Tension is then created by placing a safety pin through the knots. Dziki and Bartos [18] described a rubber-band seton technique which is tightened around the external sphincter by a thread tied around its ends. The tension in the seton can be adjusted by applying further thread ties (fig. 2b). Loberman et al. [19] described the use of a hangman's tie using a polypropylene or nylon suture (fig. 2c). Vatansev et al. [20] described the use of a synthetic cable tie manufactured from nylon. The width, length, and head part employ a ratcheting mechanism to bundle and then lock items together. Awad et al. [8] described the use of a non-toxic tin split-shot sinker (fig. 2d) to hold a 3-0 polypropylene suture on a red-rubber catheter in place. Manual compression of the sphere closes the notch and secures the line in place. Pressure applied to two steps or ears on the opposite side opens the notch, releasing the line. Cirocco and Rusin [21] described the use a common office implement, the rubber-band ligator, to manage the seton in an outpatient setting.

Variations Based on the Mechanism of Action of Seton

Conceptually, a seton can be used as a marker or a divider [22]. A seton can help stimulate fibrosis around the tract making it obvious, and thus acts as a marker of the fistula tract for sphincter-sparing procedures such as fistula plug, fibrin glue and ligation of the intersphinc-
巳 teric fistula tract. In the cutting seton technique, the seton is used purely as a divider, whereas in a staged fistulotomy, cutting of sphincter muscles occurs gradually. Advocates for staged fistulotomy using a seton state that 음 a cutting seton inflicts unnecessary pain on the patient as it pinches and abrades the edematous anoderm. Also, $\frac{0}{3}$ it is an uncontrolled method of dividing the sphincter, and it may be unsuccessful if the muscle is too thick or may lead to pressure necrosis of the full thickness of the sphincter muscle, resulting in sepsis, fecal incontinence, or both. The second-stage surgery is performed in 6-8 weeks after the first surgery to allow for adequate healing of the cephalad portion of the sphincter and to re-establish continuity of the anorectal ring [22].

In a study performed by García-Aguilar et al. [23] comparing a cutting seton versus a two-stage seton fistulotomy in surgical management of high anal fistula, the authors concluded that both techniques were equally effective in eradicating the fistula, and both were associated with a similar rate of incontinence. Hammond et al. [24] described the 'snug' seton technique using 1-mm silastic seton tied snugly around the sphincter muscles so that it abutted the enclosed tissues with only minimal tension. Walfisch et al. [25] described a double seton technique to avoid repeated treatments. Two threads of No. 0 heavy silk are passed through the tract. One of the sutures is tied and the second left untied for 1 month, at which time the first thread is removed and the second tied with local anesthesia.

Theerapol et al. [2] described the two-seton placement method, comprising of a drainage seton and a primary cutting seton using two sutures which are threaded through the internal opening. García Olmo et al. [26] described the multiple seton technique wherein five 1-0 silk sutures are passed along the fistula track (fig. 3a). At weekly intervals, each suture is tightened progressively after taking out the previously tightened suture which becomes lax. Durgun et al. [27] described the use of multiple setons (four or five No. 1 braided silk threads) as modified cutting setons along with partial fistulotomy wherein the fistula tract is laid open over a grooved probe up to the dentate line.

Lentner and Wienert [28] described the long-term, in-dwelling loose setons with polyester as a primary treatment for low trans- and intersphincteric anal fistulas wherein the average duration of seton in place was 54.8 weeks. Recurrence rates were comparable with those of primary surgically treated cases, but incontinence was rare. A loose seton is placed around the external sphincter and is not removed until the internal orifice has mi- 
Fig. 2. Maintenance of tension. a Leg strap and tourniquet technique for achieving constant tension in the seton. b Rubberband seton which is tightened around the external sphincter by progressive threads tied around its ends. c Hangman tie. d Tin split-shot sinker to hold polypropylene suture on a red-rubber catheter.
Fig. 3. Techniques to alter the mechanism of seton action. a Multiple seton technique. b Progressive migration technique. c Tube loop seton for drainage.
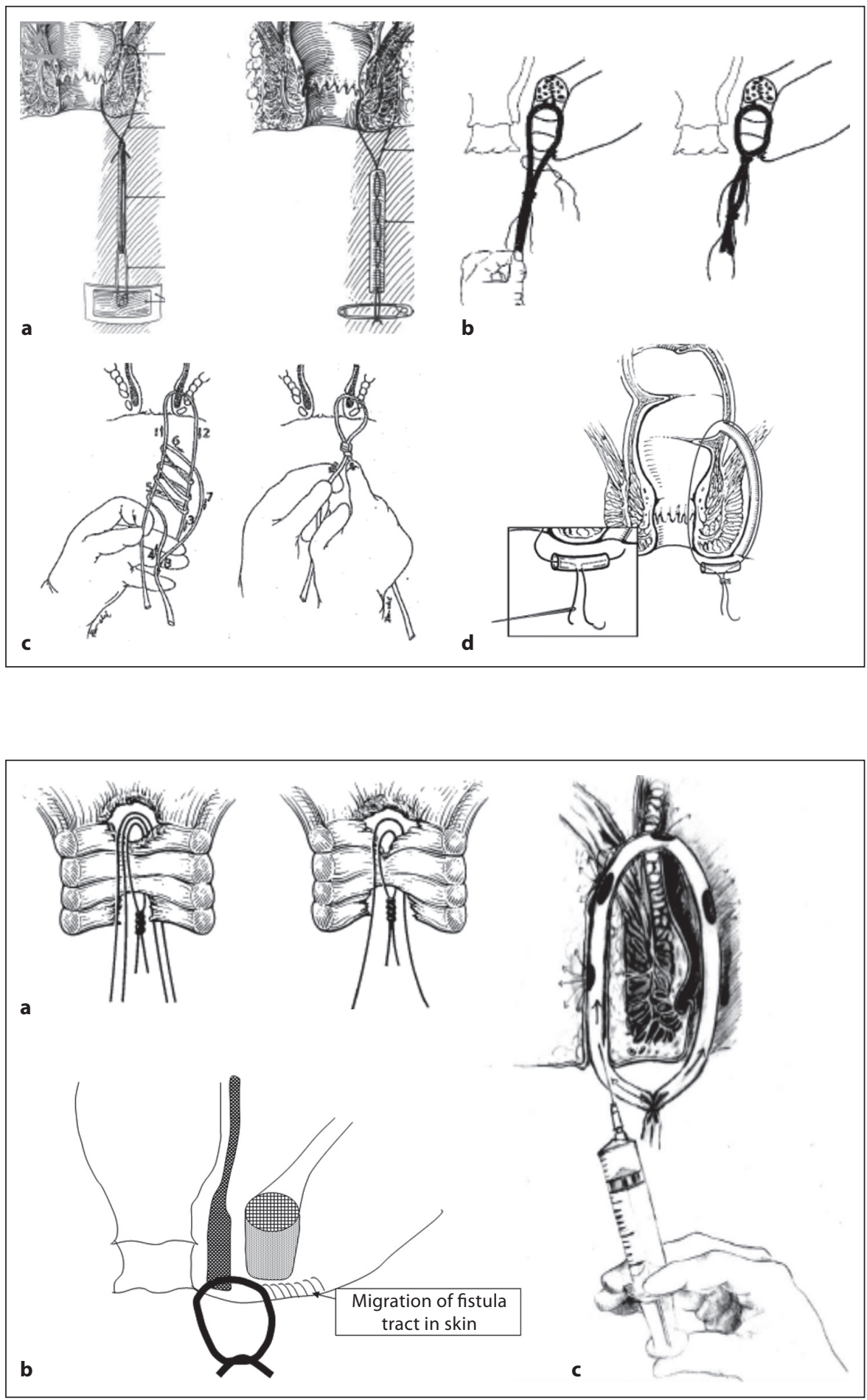

grated towards the perianal skin. Pinedo [29] described a loose elastic seton which is placed around the external sphincter. It is not tightened at any time during the follow-up and is not removed until the internal orifice has migrated towards the perianal skin, and discharge from the wound has ceased.

Pescatori et al. [30] described a combined seton-double flap procedure for complex high anal fistulas wherein 
Fig. 4. Replacement of seton. a Creation of a simple loop within the knot of the seton suture to allow a new suture to be threaded into the loop at the time of changing the seton. b Looped seton technique. c Olive-tip cannula for placement of two strands of seton, one of which is used for replacement of a new seton.

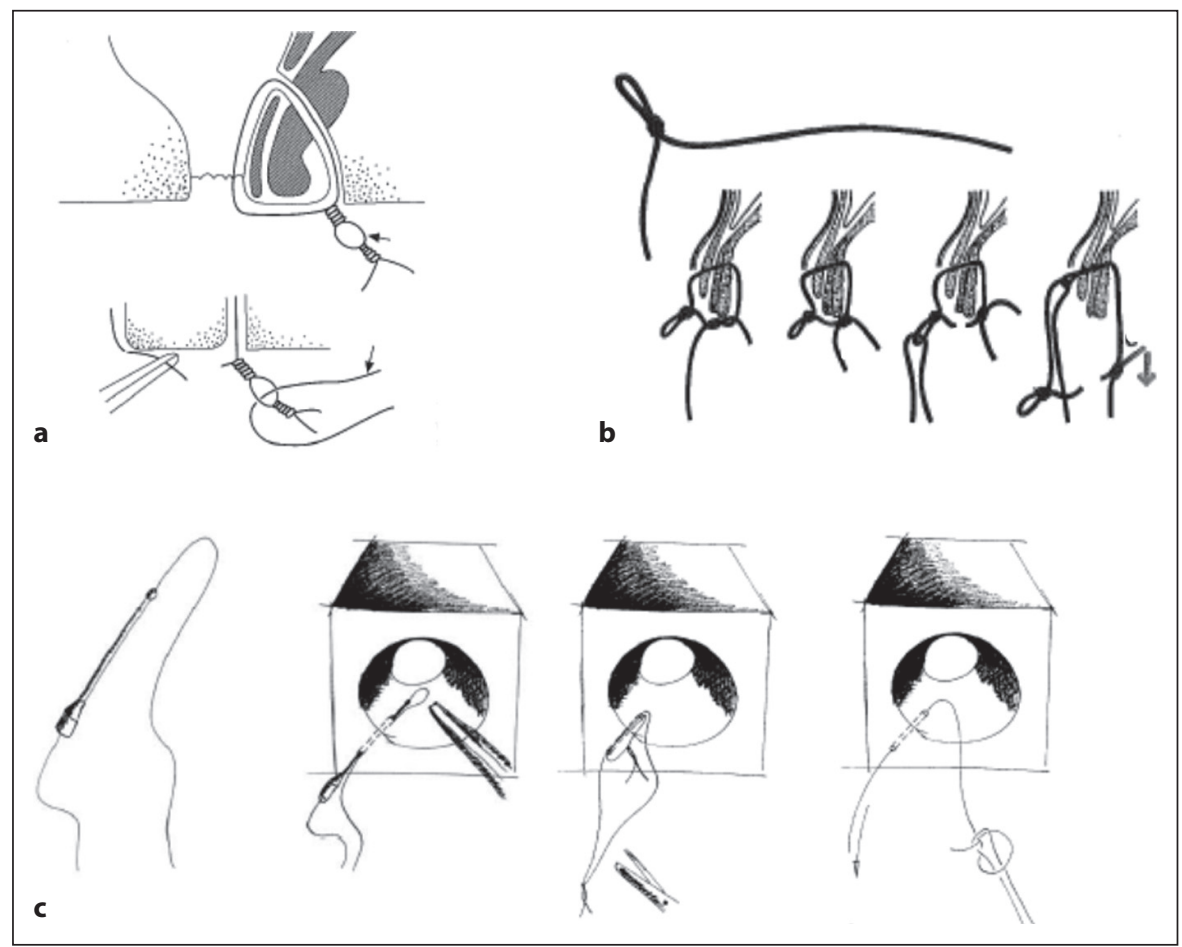

a cutting seton is placed around the external sphincter along with an advancement rectal flap. Zbar et al. [31] described the internal anal sphincter preservation with seton rerouting in high transsphincteric anal fistulas. Deliberate closure of the internal fistula opening is done with a mucosal flap. The intersphincteric space is dissected for rerouting the fistula by inserting a 0 -nylon seton suture across the external anal sphincter. The seton is passed submucosally and subcutaneously with tightening at 2-week intervals in the clinic until the seton has fully cut through. In our study on patients with high transsphincteric fistulas [32], we used silk No. 0 as setons which were loosely tied with three square knots. We asked the patients to spin the seton in $360^{\circ}$ such that the knots passed through the fistula tract twice daily. We called this the 'progressive migration technique' as the constant movement of the seton helped in gradual migration of the fistula tract (fig. $3 b$ ).

\section{Drainage Tube Technique}

Balogh [33] described the tube loop seton drainage treatment using a 16-18Ch Nelaton catheter for multiple recurring high-spreading extrasphincteric perianal fistulas (fig. 3c). The drainage loop setons make it possible to rinse the wound following fistulectomy and also the bidirectional drainage of the wound discharge. This prevents reinfection resulting from defecation, which is one of the most frequent causes of fistula recurrence.

Choi et al. [34] described the patient-performed seton irrigation technique. Several holes were made on an $8-\mathrm{mm}$ silicone Penrose drain, and a Jackson-Pratt drain was inserted and fixed at the distal one-third point of the punctured Penrose drain. The Penrose drain was inserted along the fistula path through the incision for drainage from the ischiorectal space and then placed in the posterior sagittal incision through the upper part of the external sphincter. Patients could irrigate the seton themselves by applying intermittent pressure using a syringe. Takesue et al. [9], in their study on setons in Crohn's disease, described the use of a Malecot catheter in combination with the application of the seton to facilitate drainage of the abscess.

\section{Changing the Loops}

Seow-Choen and Leong [35] described creation of a simple loop within the knot of the seton suture to allow a new suture to be threaded into the loop at the time of changing the seton (fig. 4a).

Jain and Gupta [36] described the looped seton technique (fig. 4b) as a modification of the above technique. A No. 1 silk suture is knotted to form a loop $2 \mathrm{~cm}$ long within the seton. When the seton becomes loose due to 


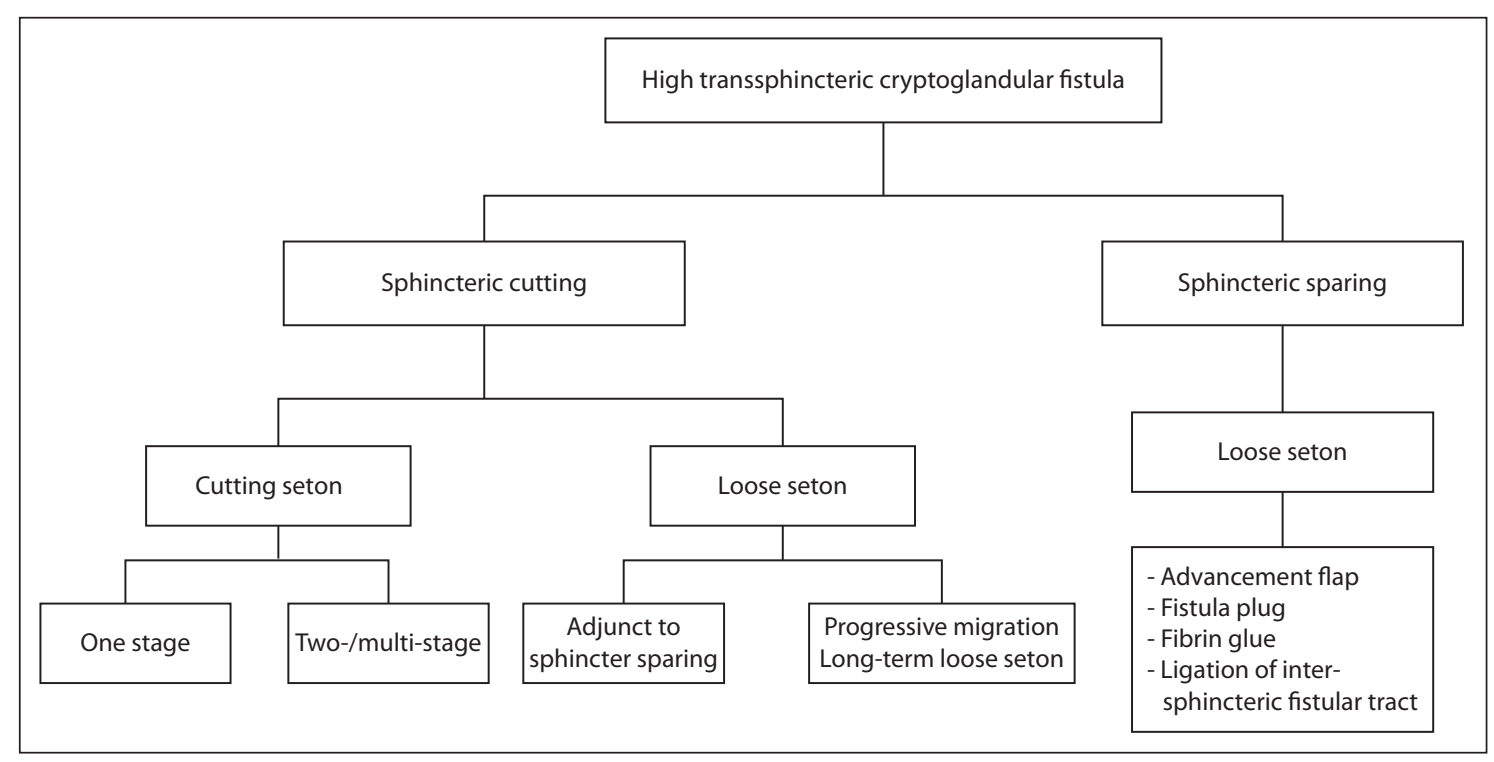

Fig. 5. Algorithm for management of high transsphincteric cryptoglandular fistula.

migration of tract, a new silk suture is threaded into the loop and this helps to re-thread the fistula tract.

Hamel et al. [37] described a technique using two sutures, one of which is tied snug to act as a cutting seton while the other suture helps in replacing the seton every 2 weeks (fig. 4c).

\section{Discussion}

This article describes the current options available for management of anal fistula with setons. When a patient presents with anal fistula, it is important to determine the level of fistula, involvement of sphincters (high vs. low transsphincteric), abscess or local sepsis and the etiology. For low fistulas involving less than one-third of the sphincters, primary fistulotomy can be performed. For high transsphincteric with abscess and local sepsis, a loose seton to act as drainage seton or a drainage tube seton should be placed. Once the abscess has been resolved for a cryptoglandular fistula the treatment decision involves the use of sphincter-sparing versus sphincter-cutting options as shown in figure 5 . Setons for such treatment can be considered either as a cutting or loose seton after discussing the individual merits with the patient. As described under variations in techniques (fig. 6), a cutting seton can be used as a single- or multi-stage procedure. Currently, cutting setons are not commonly used in developed countries because of the pain associated with treatment, uncontrolled cutting of sphincter muscles and a higher rate of incontinence. If the patient is willing to try a prolonged treatment option then he can be offered the long-term loose seton with the added option of self-spinning (progressive migration). For patients who want to opt for sphincter-saving surgery, the loose setons are generally left in the fistula tract for 4-6 weeks. Also patients who start on long-term loose seton, but do not want to continue, can be considered for sphincter-sparing surgery.

Patients with Crohn's disease have a higher risk of recurrence. Once the perianal sepsis is controlled with loose drainage setons/drainage tubes, consideration should be given for treatment with biological agents such as infliximab. Once disease and sepsis are under control, these patients can choose between either long-term loose seton or sphincter-sparing surgeries. Figure 6 summarizes the variation in materials and techniques for both cutting and loose setons.

Table 1, which provides details of any studies associated with these variations, will help in such decisionmaking. The review has some limitations as case series were not available for some of the above-mentioned variations. In the articles which had a case series, the patient population was not uniform with regard to the etiology and type of fistula, and details on incontinence and recurrence were missing in some. This made it dif- 


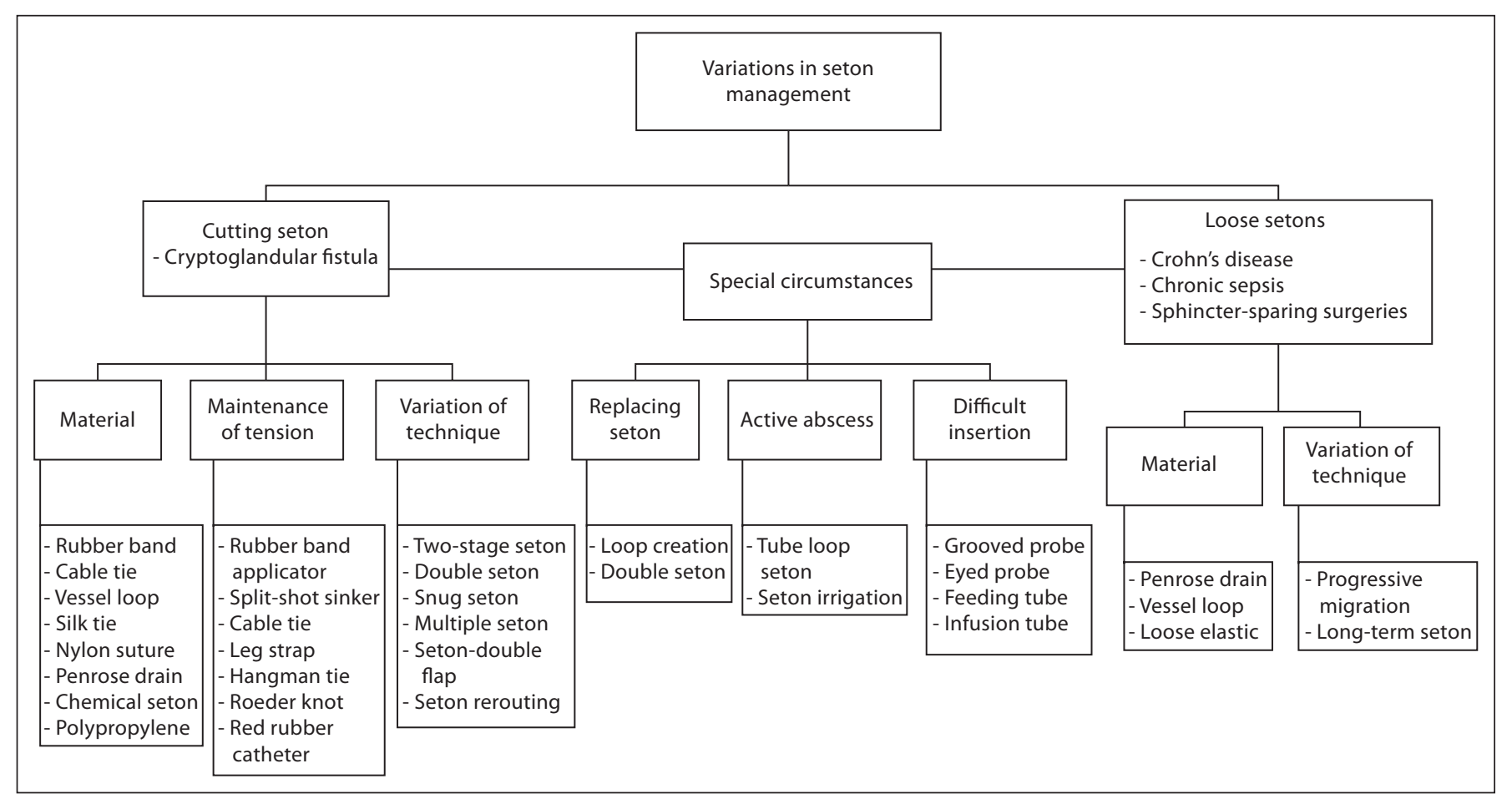

Fig. 6. Algorithm for the use of a seton in the treatment of anal fistula.

ficult to make any kind of statistical comparison between different groups based on the variations of seton management.

Most surgeons use limited variations with setons and new trainees learn what is being performed by their mentors during the training. Throughout this paper we have presented various available seton variations with regard to material, placement and maintenance techniques. This article will be helpful for those surgeons who are looking at changing their technique/material for seton treatment for reasons such as indications or a patient's condition, compliance, and results.

\section{Disclosure Statement}

The authors have no conflicts of interest to disclose.

\section{References}

1 Michalopoulos A: Perianal fistulas. Tech Coloproctol 2010;14(suppl 1):S15-S17.

$\checkmark 2$ Theerapol A, So BY, Ngoi SS: Routine use of setons for the treatment of anal fistulae. Singapore Med J 2002;43:305-307.

-3 Culp CE: Use of Penrose drains to treat certain anal fistulas: a primary operative seton. Mayo Clin Proc 1984;59:613-617.

-4 Williams JG, MacLeod CA, Rothenberger DA, Goldberg SM: Seton treatment of high anal fistulae. Br J Surg 1991;78:1159-1161.

$\checkmark 5$ Mentes BB, Oktemer S, Tezcaner T, et al: Elastic one-stage cutting seton for the treatment of high anal fistulas: preliminary results. Tech Coloproctol 2004;8:159-162.
6 Eitan A: The use of the loose seton technique as a definitive treatment for recurrent and persistent high transsphincteric anal fistulas: a long-term outcome. J Gastrointest Surg 2009;13:1116-1119.

7 Faucheron JL: Long-term seton drainage for high anal fistulas in Crohn's disease - a sphincter-saving operation? Dis Colon Rectum 1996;39:208-211.

-8 Awad ML, Sell HW, Stahlfeld KR: Split-shot sinker facilitates seton treatment of anal fistulae. Colorectal Dis 2009;11:524-526.
-9 Takesue $\mathrm{Y}$, Ohge $\mathrm{H}$, Yokoyama T, et al: Longterm results of seton drainage on complex anal fistulae in patients with Crohn's disease. J Gastroenterol 2002;37:912-915.

-10 Ho KS, Tsang C, Seow-Choen F, et al: Prospective randomised trial comparing ayurvedic cutting seton and fistulotomy for low fistula-in-ano. Tech Coloproctol 2001;5: 137-141.

11 Hanley PH: Rubber-band seton in the management of abscess-anal fistula. Ann Surg 1978;187:435-437.

12 Chuang-Wei C, Cheng-Wen H, Tsai-Yu L, et al: Cutting seton for complex anal fistulas. Surgeon 2008;6:185-188. 
13 Parks AG, Stitz RW: The treatment of high fistula-in-ano. Dis Colon Rectum 1976;19: 487-499.

14 Armstrong T, Tarver DS, Clarke AD, et al: Hollow seton for magnetic resonance imaging fistula visualization. Colorectal Dis 2006; $8: 615$.

15 Seow-Choen F: Seton insertion for difficult anal fistulas. Colorectal Dis 2003;5:373.

$>16$ Gurer A, Ozlem N, Gokakin AK, et al: A novel material in seton treatment of fistulain-ano. American J Surg 2007;193:794-796.

17 Thompson JE Jr, Bennion RS, Hilliard G: Adjustable seton in the management of complex anal fistula. Surg Gynecol Obstet 1989;169: 551-552.

18 Dziki A, Bartos M: Seton treatment of anal fistula: experience with a new modification. Eur J Surg 1998;164:543-548.

-19 Loberman Z, Har-Shai Y, Schein M, Hashmonai M: Hangman's tie simplifies seton management of anal fistula. Surg Gynecol Obstet 1993;177:413-414.

20 Vatansev C, Alabaz O, Tekin A, et al: A new seton type for the treatment of anal fistula. Dig Dis Sci 2007;52:1920-1923.

-21 Cirocco WC, Rusin LC: Simplified seton managementforcomplexanalfistulas: a novel use for the rubber band ligator. Dis Colon Rectum 1991;34:1135-1137.

-22 Pearl RK, Andrews JR, Orsay CP, et al: Role of the seton in the management of anorectal fistulas. Dis Colon Rectum 1993;36: 573-577.
23 García-Aguilar J, Belmonte C, Wong DW, et al: Cutting seton versus two-stage seton fistulotomy in the surgical management of high anal fistula. Br J Surg 1998;85:243-245.

24 Hammond TM, Knowles CH, Porrett T, Lunniss PJ: The snug seton: short- and medium-term results of slow fistulotomy for idiopathic anal fistulae. Colorectal Dis 2006;8: 328-337.

25 Walfisch S, Menachem Y, Koretz M: Double seton - a new modified approach to high transsphincteric anal fistula. Dis Colon Rectum 1997;40:731-732.

26 García Olmo D, Vázquez Aragón P, López Fando J: Multiple setons in the treatment of high perianal fistula. Br J Surg 1994;81: 136-137.

27 Durgun V, Perek A, Kapan M, et al: Partial fistulotomy and modified cutting seton procedure in the treatment of high extrasphincteric perianal fistulae. Dig Surg 2002;19: 56-58.

28 Lentner A, Wienert V: Long-term, indwelling setons for low transsphincteric and intersphincteric anal fistulas. Experience with 108 cases. Dis Colon Rectum 1996;39:1097-1101.

29 Pinedo MG: Modified loose-seton technique for the treatment of complex anal fistulas. Colorectal Dis 2010;12:e310-e313.

30 Pescatori M, Mungo M, Guarino E: Combined seton-double flap procedure for complex high anal fistula. Tech Coloproctol 2002; 6:71.
1 Zbar AP, Ramesh J, Beer-Gabel M, et al: Conventional cutting versus internal anal sphincter-preserving seton for high transsphincteric fistula: a prospective randomized manometric and clinical trial. Tech Coloproctol 2003;7:89-94.

32 Subhas G: Non-cutting setons for progressive migration of complex fistula tracts: a new spin on an old technique. Int J Colorectal Dis 2011;26:793-798.

33 Balogh G: Tube loop (seton) drainage treatment of recurrent extrasphincteric perianal fistulae. Am J Surg 1999;177:147-149.

34 Choi D, Sung Kim H, Seo HI, Oh N: Patientperformed seton irrigation for the treatment of deep horseshoe fistula. Dis Colon Rectum 2010;53:812-816.

35 Seow-Choen F, Leong F: Simple method of tightening cutting setons. Br J Surg 1994;81: 1214.

36 Jain BK, Gupta A: Simple method of tightening cutting setons. Br J Surg 1995;82:1002.

37 Hamel CT, Marti WR, Oertli D: Simplified placement and management of cutting setons in the treatment of transsphincteric anal fistula: technical note. Int J Colorectal Dis 2004;19:354-356.

38 Mohite JD, Gawai RS, Rohondia OS, Bapat RD: Ksharsootra (medicated seton) treatment for fistula-in-ano. Indian J Gastroenterol 1997;16:96-97. 